\title{
Knowledge sharing and individuals' effectiveness in educational institutions
}

\author{
Khaled Salmen Aljaaidis $^{a^{*}}$, Omar Ali Bagais ${ }^{a}$ and Ehsan Al-Moataz ${ }^{b}$
}

${ }^{a}$ Accounting Department, College of Business Administration, Prince Sattam bin Abdulaziz University, Saudi Arabia ${ }^{b}$ Accounting Department, College of Business Administration, Umm Al-Qura University, Saudi Arabia

\section{H R O N I C L E}

Article history:

Received: May 30, 2020

Received in revised format:

May 302020

Accepted: June 30, 2020

Available online:

July 1, 2020

Keywords:

Individual's effectiveness

Knowledge Sharing

Willingness and ability to share

knowledge

Accounting students

Saudi Arabia

\section{A B S T R A C T}

This study examines two models of knowledge sharing. Model 1 investigates the association of willingness to share knowledge, ability to share knowledge and knowledge sharing. Model 2 tests the individual's effectiveness as an integration term of willingness to share and ability to share with knowledge sharing. The final sample of this study consists of 204 accounting students at Umm AlGura University for the academic year 2013/2014. Using a survey-based methodology, the multiple regression of Model 1 shows that the willingness to share and the ability to share knowledge are associated positively with knowledge sharing. In addition, the result of the simple regression of Model 2 illustrates that individual's effectiveness was positively associated with knowledge sharing. The results of this study are useful for educational policy makers in Saudi Arabia and elsewhere, as there is an opportunity of enhancing the knowledge sharing in the educational context.

\section{Introduction}

Knowledge sharing is associated with exchanging information or data among workmates or members of a specific firm (Connelly \& Kelloway, 2003). Willem (2003) defines it as a knowledge interchange involving a minimum of two individuals in a give-and-take process, which allows making different senses and knowledge reshaping in different contexts. Also, knowledge sharing can be described as the process which involves two parties, the one that gives and the one that receives, and there must be an exchange for the sharing to occur (Sharratt \& Usoro, 2003). Besides, Fengjie et al. (2004) exhibit that knowledge sharing consists of parties such as an organization, individual, or a team; knowledge sharing provides a platform for an individual to transfer knowledge to a team or organization. Alternatively, knowledge sharing could also mean knowledge motivation based on how someone is obliged to add his or her perception when sharing knowledge. Therefore, higher knowledge sharing signifies a greater innovation of high quality. The effectiveness and responsiveness of an organization can be greatly improved by making sure the members sharing valuable information in a free manner avoid repetition in solving similar problems (Marks, Polak, McCoy \& Galletta, 2008). According to Gwin (2003), knowledge sharing can also be defined as a single element in a solitary cycle of creating knowledge. Also, it is considered as a process that involves the creation of mutual knowledge stock among the group members, that is, existing knowledge a member of the organization has, through interacting directly or indirectly (Yoo, Lyytinen \& Heo, 2007). Additionally, it is defined as the extent to which there is a sharing of data (Shapira, Youtie, Yogeesvaran and Jaafar, 2005). In the same way, Bircham-Connoly, Corner and Bowden (2005) describe it as a "process of capturing knowledge or moving knowledge from a source unit to a recipient unit." Besides, it exists in documents as well as people's minds and is shown through their behaviors and actions (Al-Alawi et al., 2007). 
The management of knowledge determines how sharing knowledge is considered as the most fundamental element (An Fengjie, Qiao \& Chen, 2004). There exists documentation of the positive correlation between organization performance and knowledge; as a result, knowledge sharing is among the widely discussed knowledge management activities by practitioners and researchers. Consequently, this can raise the resources of an organization as well as reduce time wastage in the process of trial and error (Amin et al., 2009). Issues associated with knowledge sharing tend to be neglected, especially in educational institutions; instead, profit-motivated organizations are given more attention (e.g., Ardichvili, Page, \& Wentling, 2003; Han \& Anantatmula, 2007; Lin, 2007a; Lin, 2007b; Riege, 2005). However, knowledge sharing has been addressed by a few researchers in the context of a classroom (Wangpipatwong, 2009; Yaghi, Barakat, Alfawaer, Shkokani \& Nassuora, 2011). Also, recent studies have established a good foundation for the effects of educational level on knowledge sharing. For instance, an individual with a high level of education is likely to share knowledge as people considered him or her as more knowledgeable (Aamir et al., 2009). Furthermore, Oosterlinck (2004) discovered that knowledge sharing is fundamental in helping students to get more feedback, which improves their study initiatives. During sessions such as tutorials and laboratory meetups, students tend to share knowledge with their colleagues through websites, software, databases, study guides, personal notes or collection, and library resources (Yuen \& Majid, 2007).

The student's willingness to share knowledge is increased by their perception that it will benefit them in the future workplace (Yuen and Majid, 2007). Besides, some researches exhibit that a person with good skills in communication is more likely to have the willingness to share knowledge (Riege, 2005; Cho, Li \& Su, 2007). This justifies the fact that it is not a guarantee for a willingness to share knowledge to make any individual participate in sharing knowledge. However, apart from having the willingness to share knowledge, any person should have the ability to share knowledge. Besides, the willingness to share knowledge cannot be linked to sharing knowledge (Wangpipatwong, 2009). According to Aljaaidi, Hassan and Al-Moataz (2019), and Hashid, Bahaj and Aljaaidi (2018), there exists an optimistic correlation betwixt willingness to share knowledge and sharing knowledge. Also, there exists a positive link between the level of the knowledge shared and willingness to share knowledge (De Hoof, Elving, Meeuwsen and Dumoulin 2003). Based on the ability to share knowledge, several studies have exhibited how it positively associate with knowledge sharing (Wangpipatwong, 2009; Hashid et al., 2018; Aljaaidi et al., 2019). An argument that the ability to share knowledge controls the correlation between willingness to share knowledge as well as knowledge sharing has been developed due to the different results of previous researches. This will make a person with good written and verbal communication skills as well as useful knowledge to have a motivation to share knowledge. Therefore, the purpose of this research is to evaluate the controlling effect of the ability to share knowledge depending on the correlation that exists between willingness to share knowledge and knowledge sharing in the context of education in Saudi Arabia, in particular Umm Al-Gura University. Also, a lack of research in knowledge sharing, in particular educational institutions, is another source of motivation for this study. For this study, accounting students have been chosen. Also, this paper is an attempt to extend the research of Wangpipatwong (2009), which was associated with a different educational setting in Saudi Arabia.

The remainder of the paper proceeds as follows. The next section briefly discusses the literature review and the hypotheses development. The third section describes the methodology. The empirical results and discussions of the study are reported in the fourth section while in the final section, conclusions and implications are drawn.

\section{Literature review and hypotheses development}

The willingness to share knowledge in any institution is perceived as a fundamental factor influencing the attitude of students towards knowledge sharing (Khyzer et al. 2009; Saffar \& Obeidat, 2020; Samadi, 2018). Students are motivated to have a willingness to share knowledge because they think it will help them in the future in regards to joining a workplace (Yuen \& Majid, 2007). According to Robbins (1993), and Ardichvili (2008), Zboralski et al. (2004), other motivations of having a willingness to share knowledge include normative and community-related considerations and personal benefits. Besides, Moghavvemi, Sharabati, Klobas, \& Sulaiman (2018) proposed that students are willing to participate in sharing knowledge when they believe or think there is an opportunity for mutual benefit. Their research corresponds to the study of Strong et al. (2008) and Shapin (1988), who discovered mutual reciprocity as one of the key factors that motivate sharing knowledge. Mayer et al. (1995) proposed that ability is a fundamental factor that emphasizes on trust associated with sharing knowledge.

Student's career environment motivates them to form an optimistic attitude towards sharing knowledge; therefore, there is an increase in their willingness to share knowledge (Yuen \& Majid, 2007). Based on the discovery of Jain et al. (2007), academic staff has a willingness to share knowledge with their colleagues at Klang Valley business school. However, low written and verbal communication skills are ranked as the second barrier to share knowledge. In the same way, other researches show that a person with good communication skills is more likely to have a willingness to share knowledge. (Riege, 2005; Cho, Li and $\mathrm{Su}, 2007)$. Also, Van De Hoof, Elving, Meeuwsen and Dumoulin (2003) suggest that the correlation between willingness to share knowledge and the ability to share knowledge is positive. This relationship ensures that there is a consistent flow of organization innovations ( $\AA \mathrm{mo}, 2006$; Kessel et al., 2012). Also, this proves that it is not a guarantee that willingness to share knowledge can make any person participate in sharing knowledge. However, apart from a willingness to share knowledge, the individual should have the ability to share knowledge. Willingness to share knowledge does not relate to knowledge sharing (Wangpipatwong, 2009; Sadq et al., 2020). On the other hand, Hashid, Bahaj and Aljaaidi (2018) discovered that the 
correlation betwixt willingness to share knowledge and sharing knowledge is positive. Besides, De Hoof, Elving, Meeuwsen and Dumoulin (2003) suggest the existence of an optimistic correlation betwixt willingness to share knowledge and the ability to share knowledge. These different perspectives of the studies trigger an argument concerning the ability to share knowledge controls the relationship betwixt willingness to share knowledge and knowledge sharing. Therefore, a person with good written and verbal communication skills, as well as useful knowledge, will have a motivation to share his or her knowledge. The above discussion makes us predict the following hypotheses:

H1: Willingness to share knowledge is positively associated with knowledge sharing.

$\mathbf{H}_{2}$ : Ability to share knowledge is positively associated with knowledge sharing.

H3: Individual's effectiveness is positively associated with knowledge sharing.

\section{Methodology}

Based on the previously cited theoretical and empirical literature (Cheng et al., 2009; Yaghi et al., 2011; Riege, 2005; Jain et al., 2007; Chen, Koch, Chung \& Lee, 2007; Han \& Anantamtmula, 2007; Lu, Leung \& Koch, 2006; Van Den Hoof \& Huysman, 2009; Wangpipatwong, 2009; Cheng et al., 2009), this study develops the following research model 1 and model 2 as shown in Fig. 1 and Fig. 2:

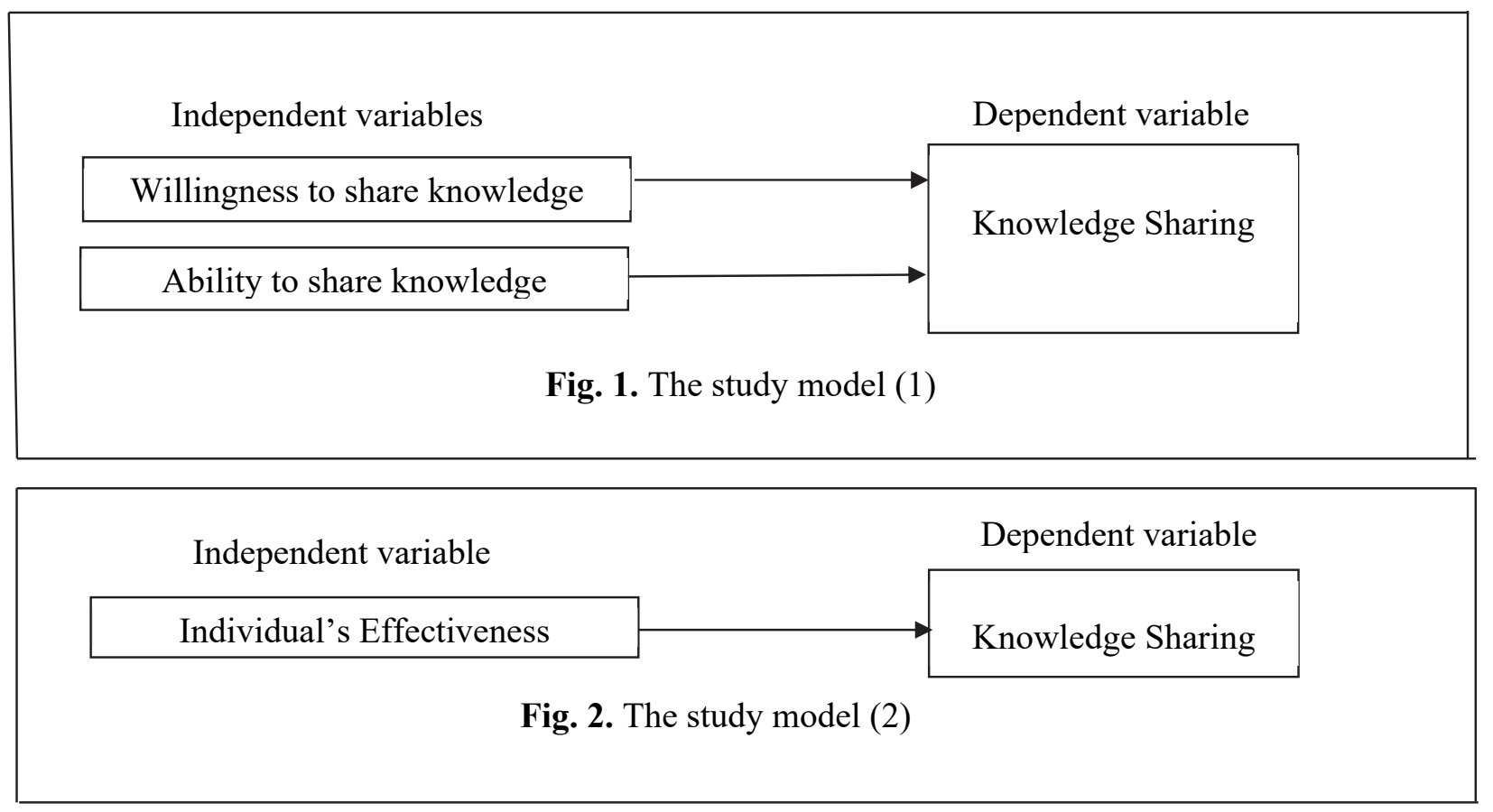

This research identified an authenticated data collection scale as a way of getting dependable information. To obtain the data from the students, who acted as a unit of analysis, a survey-based methodology was used. Consequently, this research approves and adjusts a self-administrative survey developed in the application of an educational institution context. The questionnaire consisted of two distinctive sections, that is, section A and section B. In section A, there were 9 questions intended to determine the different perspectives of the accounting students in regards to factors that influence how they share knowledge. The scale of five-point Likert was preferred in this section as the students were required to show the degree to which they agreed or disagreed with the statements in the questionnaire. Also, the questions in this section prompted for demographic features. Two hundred two accounting students enrolling for the academic year 2013/2014 at Umm Algurah University in Saudi Arabia acted as a sample for the research. In total, 280 questionnaires were circulated to all accounting students during classroom time using a simple random sampling method. The students were required to return the questionnaires after two weeks. The response rate for this study was $73 \%$. The model of this research consists of variables including a willingness to share knowledge as an independent variable, the ability to share knowledge as the moderator, and knowledge sharing, which has been used as the dependent variable. In an attempt to measure the variables, a 3-item measure was used to evaluate willingness to share as well as test the ability to share on behavior associated with knowledge sharing. Besides, an effective personal variable is measured as an interaction term betwixt willingness to share knowledge and ability to share knowledge. Also, a 3item measure is used to measure sharing knowledge sharing as a dependent variable to determine the extent to which students 
share knowledge among themselves. Each construct covered three items respectively. The respondents were asked to rate each item on a 5-point scale where 1 = "strongly disagree", $2=$ "disagree", $3=$ "neither agree nor disagree" $4=$ "agree", and 5 $=$ "strongly agree". The functional equation of regression models is utilized to determine the extent of the association of each of the independent variable on knowledge sharing as shown in Eq. (1) and Eq. (2):

$$
\begin{aligned}
& K S=\beta_{0}+\beta_{1} \text { Willingness }+\beta_{2} \text { Ability }+e, \\
& K S=\beta_{0}+\beta_{1} I E+e,
\end{aligned}
$$

where Willingness, Ability and IE represent willingness to share knowledge, ability to share knowledge and Individual's effectiveness, respectively.

\section{Empirical results and discussions}

\subsection{Descriptive Statistics and Correlation Analysis}

\subsubsection{Respondent's Profile}

Demographic characteristics of students in this study are age, level of study and CGPA as shown in Fig. 3.

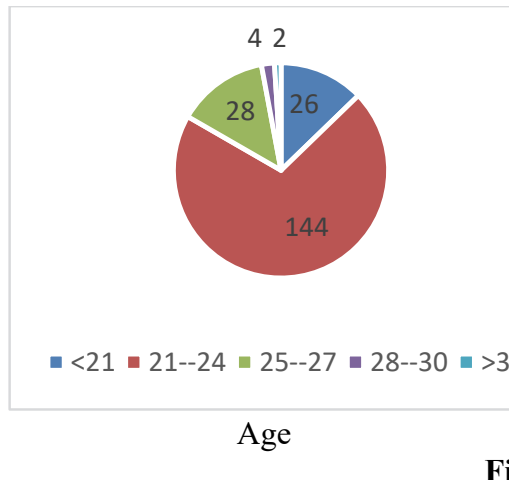

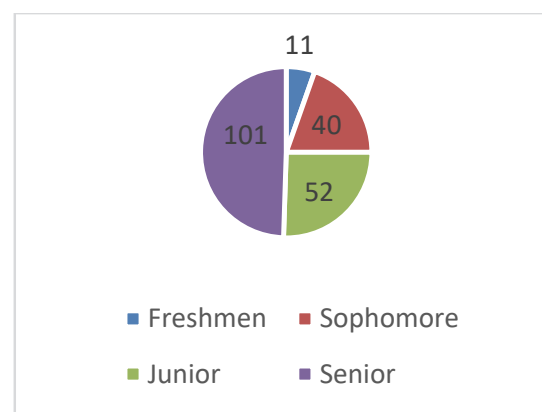

Level of study

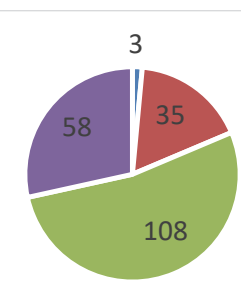

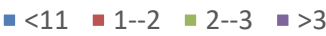

Fig. 3. Personal characteristics of the participants

Based on the demographic information depicted in Fig. 3, the majority of students (70.6\%) were between 21 and less than 24 years. The highest number of students $(49.5 \%)$ comprise of senior students. In terms of CGPA, the majority of students $(52.9 \%)$ obtained between 2 and less than 3 cumulative grade point average.

\subsubsection{Correlation Analysis}

\subsubsection{Correlation matrix}

Tables 1 displays the Pearson correlations among the hypothesized variables. The coefficients of correlation are small. The highest correlation between Willingness and Ability was $\left(.351^{* *}\right)$, indicating that the sample has no multicollinearity, since none of the correlation is equal or above 0.80 or 0.90 .

Table 1

Pearson Correlation Analysis Results

\begin{tabular}{ccc}
\hline & Willingness & Ability \\
\hline Willingness & 1 & $.351^{* *}$ \\
Ability & 1 \\
\hline
\end{tabular}

** Significant at 1 per cent level (2-tailed).

*Significant at 5 per cent level (2-tailed).

\subsubsection{Variance Inflation Factor Analysis}

As for the Variance Inflation Factor (VIF), Tables 2 reports the results as follows:

Table 2

Variance Inflation Factor (VIF)

\begin{tabular}{ccc}
\hline Variables & Tolerance & VIF \\
\hline Willingness & .877 & 1.141 \\
Ability & .877 & 1.141 \\
\hline
\end{tabular}


Table 2 illustrates that the largest VIF value is 1.141, implying that the sample has no multicollinearity, since none of the VIF values is up to 10 (Hair et al., 2006)

\subsection{Reliability Test}

The dependent and independent variables examined in this study were tested for their reliability as shown in Table 4 . The reliability indicates to the accuracy which concern on stability, dependability and consistency of an instrument. In this study, the Cronbach's alpha coefficient is used, which is based on the average correlation of items within a test if the items are standardized. Hari, Anderson, Tatham and Black (1998) document that the lower limit of acceptability may be .60.

Table 3

Mean scores and analysis of internal consistency

\begin{tabular}{ccccc}
\hline Variables & No. of Items & Mean & SD & Cronbach's Alpha \\
\hline Willingness to share & 3 & 3.837 & .678 & .726 \\
Ability to share & 3 & 3.407 & .751 & .626 \\
Knowledge sharing & 3 & 3.494 & .818 & .704 \\
\hline
\end{tabular}

As displayed by Table 3 that all the alpha coefficients exceed the recommended minimum cutoff level of .60. Thus, the items measuring the variables are considered acceptable. In another word, the instruments are reasonably accepted for the purpose of reliability.

\subsection{Regressions' Results}

Table 4 shows that the coefficient of determination $\left(R^{2}\right)$ for Model (1) is equal to 19.6 per cent which means that all the variables accounted for $19.6 \%$ of the variance in knowledge sharing.

Table 4

Summary of the model 1

\begin{tabular}{ccccc}
\hline $\mathbf{R}$ & R square & Adjusted R square & F & Sig. \\
\hline .443 & .196 & .188 & 24.324 & .000 \\
\hline
\end{tabular}

Table 4 also depicts that the model is a statistically significant where the $F$ test statistic $=24.324$ with a p-value $<0.000$.

Table 5

The results of the regression - Model 1

\begin{tabular}{ccccccc}
\hline Variables & Expected sign & Coeff. & $\boldsymbol{t}$ & $\boldsymbol{p}$-value & Tolerance & VIF \\
\hline (Constant) & & 1.354 & 4.293 & .000 & & \\
Willingness to share & + & .297 & 4.371 & .000 & .877 & 1.141 \\
Ability to share & + & .241 & 3.554 & .000 & .877 & 1.141 \\
\hline
\end{tabular}

Table 5 shows the beta coefficients for the independent variables. The largest $t$ statistics is $4.371(p$-value $<0.000)$ which is the willingness to share knowledge. This indicates that the accounting students' willingness to share knowledge has a degree of importance in explaining the knowledge sharing behavior. This result is similar to that found by Hashid et al. (2018) and Aljaaidi et al. (2019). Thus, hypotheses $\mathrm{H}_{1}$ is accepted. The second largest $t$ statistics is $3.554(p$-value $<0.000)$ which is the ability to share knowledge. This shows that the accounting students' ability to share knowledge has a significantly positive association with knowledge sharing behavior. This result is consistent with Wangpipatwong (2009), Aljaaidi et al. (2019) and Hashid et al. (2018). Thus, hypotheses $\mathrm{H}_{2}$ is supported. Table 6 shows that the coefficient of determination $\left(R^{2}\right)$ for Model (2) is equal to 19.7 per cent which means that the independent variable accounted for $19.7 \%$ of the variance in knowledge sharing.

Table 6

Summary of the model 2

\begin{tabular}{ccccc}
\hline R & R square & Adjusted R square & F & Sig. \\
\hline .444 & .197 & .193 & 49.183 & .000 \\
\hline
\end{tabular}

Table 7 also depicts that the model is a statistically significant where the $F$ test statistic $=49.183$ with a p-value $<0.000$.

Table 7

The results of the regression - Model 2

\begin{tabular}{ccccc}
\hline Variables & Expected sign & Coeff. & $\boldsymbol{t}$ & $\boldsymbol{p}$-value \\
\hline (Constant) & & 3.517 & 71.047 & .000 \\
IE & + & .444 & 7.013 & .000 \\
\hline
\end{tabular}


Table 8 shows the beta coefficients for the independent variable, individual's effectiveness $I E$. The $t$ statistics of the $I E$ is 7.013 ( $p$-value $<0.000)$. This indicates that the accounting students' individual's effectiveness a degree of importance in explaining the knowledge sharing behavior. This result is similar to that found by Wangpipatwong (2009), Aljaaidi et al. (2019) and Hashid et al. (2018). Thus, hypotheses $\mathrm{H}_{3}$ is supported.

\section{Conclusion and implication}

The purpose of the research has involved the evaluation of the two models of sharing knowledge. The first model has explored the relationship between willingness to share knowledge and the ability to share knowledge. The second model aims to test an individual's effectiveness in sharing knowledge. To accomplish this, a sample of 204 accounting students, academic year 2013/2014 at Umm Al-Gura University in Saudi Arabia, has been used to distribute out a survey questionnaire as a way of data collection. Based on multiple analyses for the first model, this research discovers the willingness to share knowledge and the ability to share knowledge correlate in an optimistic way with sharing knowledge among the accounting students. Besides, simple regression for the second model shows that the individual's effectiveness associates positively with sharing knowledge. This suggests the existence of a positive correlation between willingness share knowledge and the ability to share knowledge. The lack of a formal research body that addresses issues of knowledge sharing in the Kingdom of Saudi Arabia will motivate researchers, educational policymakers, and the academic community to take an interest in the results of this research. Therefore, this study will establish significant information in regards to issues in the educational context of Saudi Arabia, which can be used in the future as a premise data. This research suggests that lecturers at the university should encourage their students to participate in library activities as well as assign library hours in the schedule of the students. Furthermore, other colleges should hold workshops, conferences, and seminars to improve the ability of the students. Also, there should be an attempt to update and maintain the pace of the current issues and developments in academic databases and research. Various factors addressed in the two models could contribute to one of the research limitations. Besides, future research lines could present other classroom and individual elements, including library databases, IT applications, and an individual attitude. Also, future research lines may explore the behavior of knowledge sharing among administrative and academic staff. These models could be simulated to establish their viability in divergent contexts of GCC countries, in diverse periods, and with different size of the sample. These limitations may act as a motivation for future study in GCC setting.

\section{Acknowledgement}

This publication was supported by the Deanship of Scientific Research at Prince Sattam bin Abdulaziz University, Alkharj, Saudi Arabia.

\section{References}

Al-Alawi, A. I., Al-Marzooqi, N. Y., \& Mohammed, Y. F. (2007). Organizational culture and knowledge sharing: critical success factors. Journal of Knowledge Management, 11(2): 22-42.

Aljaaidi, K., Hassan, W. \& Al-Moataz, E. (2019). Knowledge sharing among accounting students: Evidence from Umm Algurah University. Economic Development Review, 4(7).

Amin, A., Hassan, M. F., Ariffin, M. B., \& Rehman, M. (2009, November). Theoretical framework of the effect of extrinsic rewards on individual's attitude towards knowledge sharing and the role of intrinsic attributes. In 2009 International Conference on Computer Technology and Development (Vol. 2, pp. 240-243). IEEE.

Åmo, B. (2006). Employee innovation behavior in health care: the influence from management and colleagues. International Nursing Review, 53(3), 231-237.

Ardichvili, A. (2008). Learning and knowledge-sharing in virtual communities of practice. Advances in Developing Human Resources, 10(4), 541-554.

Ardichvili, A., Page, V., \& Wentling, T. (2003). Motivation and barriers to participation in virtual knowledge-sharing communities of practice. Journal of Knowledge Management, 7(1), 64-77.

Bhatt, G. D. (2001). Knowledge management in organizations: Examining the interaction between technologies, techniques, and people. Journal of Knowledge Management, 5(1), 68-75.

Bircham-Connolly, H., Corner, J., \& Bowden, S. (2005). An empirical study of the impact of question structure on recipient attitude during knowledge sharing. Electronic Journal of Knowledge Management, 32(1), 1-10.

Chen, J., Koch, P., Chung, M., \& Lee, C. (2007). Exploring contributory factors in student-to-student knowledge sharing: A Singaporean perspective. Paper presented at the annual meeting of the NCA 93rd Annual Convention, Nov 14, 2007, TBA, Chicago, IL.

Cheng, M. Y., Ho, J. S. Y., \& Lau, P. M. (2009). Knowledge sharing in academic institutions: a study of Multimedia University Malaysia. Electronic Journal of Knowledge Management, 7(3), 313-324.

Cho, N., Li, G. Z., \& Su, C. -Z. (2007). An empirical study on the effect of individual factors on knowledge sharing by knowledge type. Journal of Global Business and Technology, 3(2), 1-15.

Connelly, C. E., \& Kelloway, E. K. (2003). Predictors of employees' perceptions of knowledge sharing cultures. Leadership \& Organization Development Journal. 
Fengjie, A., Fei, Q., \& Xin, C. (2004). Knowledge sharing and web-based knowledge-sharing platform. In E-Commerce Technology for Dynamic E-Business, 2004. IEEE International Conference on (pp. 278-281). IEEE.

Gwin, C. (2003). Sharing knowledge: innovations and remaining challenges: an OED evaluation. World Bank-free PDF.

Hair, J. F., Anderson, R. E., Tatham, R. L., \& William, C. (1998). Black (1998), Multivariate data analysis.

Han, B. M., \& Anantatmula, V. S. (2007). Knowledge sharing in large IT organizations: A case study. VINE: The Journal of Information and Knowledge Management Systems, 37(4), 421-439.

Hashid, A., Aljaaidi, K. \& Bahaj, S. (2018). Knowledge Sharing Among Students at Prince Sattam Bin Abdulaziz University: Empirical Evidence from College of Business Administration. Journal of Economic Additions, 2(3), 351-335.

Jain, K. K., Sandhu, M. S., \& Sidhu, G. K. (2007). Knowledge sharing among academic staff: A case study of business schools in Klang Valley, Malaysia (Doctoral dissertation, UCSI Centre for Research Excellence).

Kessel, M., Hannemann-Weber, H., \& Kratzer, J. (2012). Innovative work behavior in healthcare: The benefit of operational guidelines in the treatment of rare diseases. Health Policy (Amsterdam), 105(2-3), 146-153.

Khyzer, M.D., Asim, K.M., Zulfiqar, A., Zafar, A., Musarrat, M.N., Ishraf, A., Ahmed, U. and Naveed, A. (2009), Interpersonal factors and tendencies to knowledge-sharing among students: a case of Punjab University. The Knowledge Economy, 1(1), 519-525.

Lin, C. P. (2007a). To share or not to share: modeling knowledge sharing using exchange ideology as a moderator. Personnel Review, 36(3), 457-475.

Lin, H. F. (2007b). Effects of extrinsic and intrinsic motivation on employee knowledge sharing intentions. Journal of Information Science, 33(2), 135-149.

Marks, P., Polak, P., McCoy, S., \& Galletta, D. (2008). Sharing knowledge. Communications of the ACM, 51(2), $60-65$.

Mayer, R. C., Davis, J. H., \& Schoorman, F. D. (1995). An integrative model of organizational trust. Academy of Management Review, 20(3), 709-734.

Moghavvemi, S., Sharabati, M., Klobas, J. E., \& Sulaiman, A. (2018). Effect of trust and perceived reciprocal benefit on students' knowledge sharing via facebook and academic performance.

Oosterlinck, A. (2004). The modern university and its main activities. Reinventing the research university, 119.

Riege, A. (2005). Three-dozen knowledge-sharing barriers managers must consider. Journal of knowledge management, 9(3), 18-35.

Robbins, S. (1993). Organizational Behavior. Prentice-Hall, Englewood Cliffs, NJ.

Saffar, N., \& Obeidat, A. (2020). The effect of total quality management practices on employee performance: The moderating role of knowledge sharing. Management Science Letters, 10(1), 77-90.

Samadi, S. (2018). Theory of planned behavior and knowledge sharing among nurses in patient computer management system: The role of distributive justice. Management Science Letters, 8(5), 427-436.

Sadq, Z., Othman, B., \& Mohammed, H. (2020). Attitudes of managers in the Iraqi Kurdistan region private banks towards the impact of knowledge management on organizational effectiveness. Management Science Letters, 10(8), $1835-1842$.

Shapin, S. (1988). The house of experiment in seventeenth-century England. Isis, 79(3), 373-404.

Shapira, P., Youtie, J., Yogeesvaran, K., \& Jaafar, Z. (2006). Knowledge economy measurement: Methods, results and insights from the Malaysian Knowledge Content Study. Research Policy, 35(10), 1522-1537.

Strong, B., Davenport, T. H., \& Prusak, L. (2008). Organizational governance of knowledge and learning. Knowledge and Process Management, 15(2), 150-157.

Van den Hooff, B., Elving, W., Meeuwsen, M., \& Dumoulin, C. (2003). Knowledge sharing in knowledge communities. In Huysman, M., Wenger, E., Wulf, V. (Eds), Communities andTechnologies. The Netherlands: Kluwer, 119-141.

Wangpipatwong, S. (2009). Factors influencing knowledge sharing among university students. In Proceedings of the 17th International Conference on Computers in Education.

Willem, A. (2003). The role of organization specific integration mechanisms in inter-unit knowledge sharing. PhD Dissertation at Vlerick Leuven Gent Management School, Ghent University, Belgium, available online at http://72.14.203.104/search?q=cache:AwAf_ok1x7UJ: www.ofenhandwerk.com/oklc/pdf

Yaghi, K., Barakat, S., Alfawaer, Z. M., Shkokani, M., \& Nassuora, A. (2011). Knowledge sharing degree among the undergraduate students: a case study at applied science private university. International Journal of Academic Research, 3, 20-4

Yaghi, K., Barakat, S., Alfawaer, Z. M., Shkokani, M., \& Nassuora, A. (2011). Knowledge sharing degree among the undergraduate students: a case study at applied science private university. International Journal of Academic Research, 3, 20-4.

Yang, J. T. (2007). The impact of knowledge sharing on organizational learning and effectiveness. Journal of Knowledge Management, 11(2), 83-90.

Yoo, Y., Lyytinen, K., \& Heo, D. (2007). Closing the gap: towards a process model of post-merger knowledge sharing. Information Systems Journal, 17(4), 321-347.

Yuen, T. J., \& Majid, M. S. (2007). Knowledge-sharing patterns of undergraduate students in Singapore. Library Review, 56(6), 485-494.

Zboralski, K., Gemuenden, H.G. and Lettl, C. (2004), “A members' perspective on the success of communities of practice: preliminary empirical results", Proceedings of the 5th European Conference on Organizational Knowledge, Learning and Capabilities, Innsbruck, available at: www2.warwick.ac.uk/fac/soc/wbs/conf/olkc/archive/oklc5/papers/e-4_zboralski.pdf

(accessed 23 August 2014). 
(C) 2020 by the authors; licensee Growing Science, Canada. This is an open access article distributed under the terms and conditions of the Creative Commons Attribution (CC-BY) license (http://creativecommons.org/licenses/by/4.0/). 